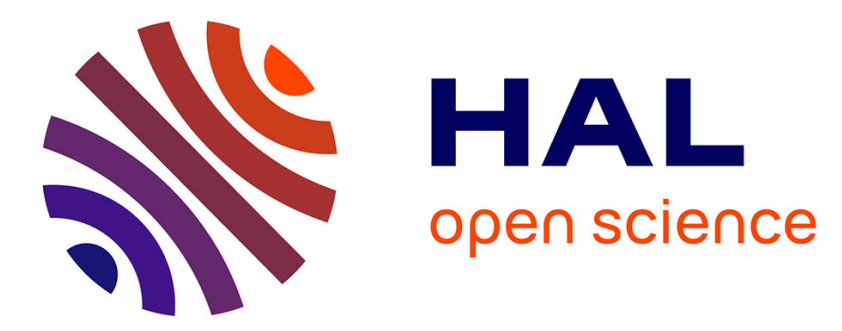

\title{
A Methodology to Build a Framework for Collaboration Performance Assessment in PSS Delivery
}

Mourad Harrat, Farouk Belkadi, Alain Bernard

\section{To cite this version:}

Mourad Harrat, Farouk Belkadi, Alain Bernard. A Methodology to Build a Framework for Collaboration Performance Assessment in PSS Delivery. IFIP Advances in Information and Communication Technology, 2021, pp.181 - 191. 10.1007/978-3-030-85902-2_20 . hal-03544718

\author{
HAL Id: hal-03544718 \\ https://hal.science/hal-03544718
}

Submitted on 26 Jan 2022

HAL is a multi-disciplinary open access archive for the deposit and dissemination of scientific research documents, whether they are published or not. The documents may come from teaching and research institutions in France or abroad, or from public or private research centers.
L'archive ouverte pluridisciplinaire HAL, est destinée au dépôt et à la diffusion de documents scientifiques de niveau recherche, publiés ou non, émanant des établissements d'enseignement et de recherche français ou étrangers, des laboratoires publics ou privés. 


\title{
A Methodology to Build a Framework for Collaboration Performance Assessment in PSS Delivery
}

\author{
Mourad Harrat ${ }^{(\otimes)}$, Farouk Belkadi, and Alain Bernard \\ Ecole Centrale de Nantes, Laboratory of Digital Sciences of Nantes, \\ LS2N UMR 6004, Nantes, France \\ \{mourad.harrat, farouk. belkadi, alain. bernard\}als2n.fr
}

\begin{abstract}
Companies are more and more seeking for external partners in order to manage new solutions at their development and use phases, especially when the type of these solutions is Product-Service Systems (PSS). PSS have some organizational particularities which increase the complexity of collaboration processes. In this context, collaborating efficiently with the different partners is a key aspect to reduce the risk of failure of PSS projects, and is influenced by various organizational factors and practices. This paper proposes a methodology in four steps to build a decision-aid framework supporting collaboration assessment and management in the presented context. Important factors and performance indicators are identified based on literature review and industrial practices. Then, Fuzzy techniques as well as decision trees are used to build the assessment systems. Three case studies are conducted to explore industrial practices and to confront the different elements of the proposed framework, and finally to validate the assessment framework.
\end{abstract}

Keywords: Collaboration · Product-Service Systems (PSS) · Assessment

\section{Introduction}

Product-Service Systems (PSS) can be defined as a combination of tangible products and intangible services which jointly responds to customer's needs [1]. Compared to pure products, these business models have an increased complexity and require multidisciplinary domains and competences along its whole lifecycle [2], which can be hardly held without the involvement of external partners. Thus, PSS contexts necessitate closer relationships with the different stakeholders, entailing a shift from a transactional to relational orientated partnerships [3]. This is due to the organizational differences induced by servitized environments, such as in contract management, life-cycle management, degree of data collection from customer, etc. [2]. Consequently, collaborations become a central aspect to manage in order to ensure the success of PSS development and use phases. To achieve effective collaborations in PSS context, two different aspects need to 
be explored and timely operationalized: (1) the factors influencing on inter-firm collaboration performance, and (2) the organizational practices suggested in PSS situations. The operationalization of these aspects can be performed by defining some relevant Key Performance Indicators (KPIs) and enabling an assessment process. Most of existing research works which established assessment frameworks for PSS context, focused on aspects such as design, functionalities, sustainability, customer satisfaction, maintenance, etc. [4]. In difference with classical New Product Development (NPD) projects, studies addressing collaboration performance assessment in PSS are still limited. For example, some authors dealt with the evaluation of collaborative networks readiness [5]. However, the literature is missing an extensive framework to assess collaboration performance for PSS contexts. To deal with this gap, this paper introduces a methodology for building such framework. The collaboration problem and context are clarified in Sect. 2. Then, the methodology is explained progressively in Sect. 3. An ongoing validation process is detailed in the conclusion.

\section{Inter-firm Collaboration Within PSS Context}

Before any partnership, and particularly to carry on PSS development and use phases, a recurring problem for firms is how to choose the relevant partners and how to ensure that these partners are able to participate in a collaborative PSS delivery. This ability translates into a set of capabilities and competences related to PSS which are required for each collaborating party. However, assessing a partner based solely on his competences is not sufficient, because the causes of an occurring problem during the collaboration can be beyond the control of the partner and being more related to the relationship [6] (Fig. 1).

For example, some important criteria of success as efficient tasks coordination, an appropriate communication frequency, well-established routines of knowledge sharing, and an atmosphere of trust are needed to avoid risks of project failure. This requires an assessment at each step of the collaboration process.

Consequently, an assessment during collaboration is necessary. The assessment framework in this step is not only based on collaboration factors as mentioned above, but also on PSS organizational practices. Indeed, PSS business models have some particularities that we need to consider in this assessment process. One of these particularities is the necessity of a whole life-cycle consideration with long-term relationships with partners $[7,8]$, as the collaboration process is extended beyond the sale of the product. This implies the necessity to involve all supply chain partners in early design, which may include maintenance and after sales services [2,3]. Another particularity is that contractual mechanisms of PSS show higher complexity regarding terms and agreements, with higher risk levels which is shared throughout the life-cycle $[9,10]$. The permanent evolution of the PSS is also another characteristic of PSS, requiring closer interactions with customers [2,9], and higher levels of adapting common standards and processes [10]. 


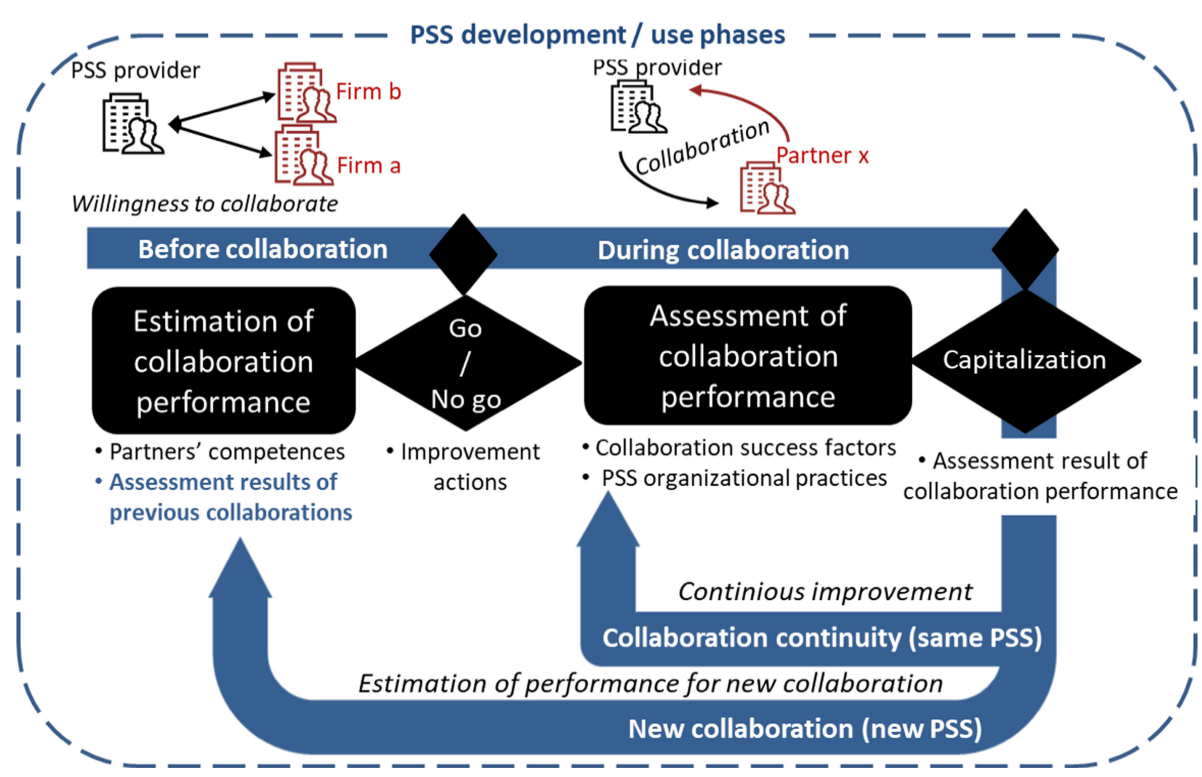

Fig. 1. Assessment cycle of collaboration performance in PSS context

\section{A Methodology for Building a Framework to Assess Collaboration Performance}

The proposed methodology takes place in four main steps, which are presented in the following sub-sections. A fifth step which concerns the validation of the framework in is explained in conclusion as a work in progress.

\subsection{Identification of Factors Impacting Collaboration Performance}

The first step was to identify factors leading to successful collaboration. Here, a focus should be done on the performance of relationships between partners rather than the particular partners' performance only $[6,11]$. Thus, we performed a literature review from a selection of 60 articles dealing with collaboration factors, chosen according to three criteria: (1) the addressed subject is about collaboration success factors; (2) the addressed context is collaboration between industrial organizations; and (3) the dependent variables or addressed concepts have a close meaning or similar characteristics to "collaboration performance". Thus, 41 factors were identified and then grouped into main categories. After that we filtered them according to three criteria: (1) the frequency of citation; (2) the adaptation to the context of the framework (inter-organizational collaboration, without including inter-personal factors); and finally (3) the significance of the impact of these factors by checking the consistency of the different studies. The references and more details of this literature review are mentioned by Harrat et al. (2020) [12], and cannot be cited in this paper due to its size limitation. This review resulted on 
10 retained factors which are: trust, commitment, shared vision and values, shared language, knowledge sharing, shared goals and interests, social network ties, coordination, communication quality, and interdependence.

\subsection{Case Studies Presentation and Validation Process}

In order to validate the list of factors and to consolidate the whole framework, three case studies were conducted by means of 5 different interviews (Table 1).

Table 1. Details of the exploratory case study conducted

\begin{tabular}{|c|c|c|c|c|c|}
\hline Case & PSS name & PSS type & Interview with & Business area & Main activity \\
\hline \multirow[t]{2}{*}{ Case A } & \multirow[t]{2}{*}{$\begin{array}{l}\text { Connected } \\
\text { shoe }\end{array}$} & \multirow[t]{2}{*}{ Product-oriented } & 1-OEM & $\begin{array}{l}\text { Leather and } \\
\text { shoes }\end{array}$ & $\begin{array}{l}\text { Shoe } \\
\text { manufacturer }\end{array}$ \\
\hline & & & $\begin{array}{l}\text { 2-Consulting } \\
\text { Partner }\end{array}$ & Electronics & IoT assistance \\
\hline \multirow[t]{2}{*}{ Case B } & \multirow[t]{2}{*}{$\begin{array}{l}\text { Drilling } \\
\text { robot }\end{array}$} & \multirow[t]{2}{*}{ Use-oriented } & 1- OEM & $\begin{array}{l}\text { Construction } \\
\text { and public } \\
\text { works }\end{array}$ & Public works \\
\hline & & & 2-Supplier & Robotics & Robot provider \\
\hline Case C & $\begin{array}{l}\text { Surgery } \\
\text { robot }\end{array}$ & Product-oriented & Supplier & Robotics & Robot provider \\
\hline
\end{tabular}

Case A concerns the development project of a connected shoe, with the ability to detect falls and alert the emergency services. Since the latter services are integrated, the solution is considered as a product oriented-oriented PSS.

Case B is about the development project of a robot that ensures the drilling activity in construction sites. This robot is intended to be rented to construction sites according to their drilling needs. It is then considered as a use-oriented PSS.

Case $\mathrm{C}$ concerns the development project of a mobile robot providing support for surgical and imagery activities in an operating theater. This robot is sold by the OEM with assistance services, so it is considered as a product-oriented PSS.

Through semi structural interviews, the industrials were first questioned about different aspects, and especially the factors that are in relation with their collaboration performance. Except case $\mathrm{C}$ where there were globally no collaborative issues, the other cases present some considerable challenges.

In Case A, some trust issues were mentioned by the interviewee, between the OEM and the electronic design partner. The latter was considering his own constraints and was not able to adapt the solution to the OEM needs. Thus, the relationship was not balanced as described by the interviewee, which leaded the OEM to search for new partners in the project. On the other hand, Case B had a similar problem as Case A, as the specifications of the OEM did not meet the standards of his robot supplier. The ground clearance of the robot had to be high enough to be able to work in varied terrain, which was not in 
accordance with the standards of the supplier. The latter required a minimum height to ensure the safety of the operators. The OEM ended up accepting this constraint and the design was pursued and a final prototype was developed. At the end, the interviewee mentioned that the prototype was finally "a failure". This lets them to consider preparing a new project in future with a new supplier and a different design.

During the interviews, the industrials were asked to assess the importance of the different factors arose from our literature review. As a result of this assessment, we performed a second filtering of the factors, by keeping the ones considered most important according to the industrials, which are: trust, commitment, communication quality, project coordination and shared language.

\subsection{KPIs Building and Validation}

After validating the list of factors, the next step is to build the corresponding KPIs, by defining quantitative measures as percentages. This form of measure allows us to counter the subjectivity biases of human factors. The KPIs we define are adapted from indicators that are already validated by the literature. For each factor, we use references from both a PSS and a generic perspective to express the KPIs.

Table 2. KPIs adapted from authors corresponding to collaboration performance factors

\begin{tabular}{|c|c|c|c|}
\hline Factors & Corresponding KPIs & $\begin{array}{l}\text { References with a } \\
\text { generic perspective }\end{array}$ & $\begin{array}{l}\text { References with a PSS } \\
\text { perspective }\end{array}$ \\
\hline \multirow[t]{4}{*}{ Trust } & Pre-transaction costs & {$[13]$} & \multirow{7}{*}{$\begin{array}{l}\text { Same KPIs for social } \\
\text { capital (e.g. trust, } \\
\text { commitment) are } \\
\text { applied in PSS } \\
\text { perspective, according to } \\
\text { Zhang (2017) [7] }\end{array}$} \\
\hline & Post-transaction costs & {$[13]$} & \\
\hline & $\begin{array}{l}\text { History of } \\
\text { collaboration }\end{array}$ & {$[14]$} & \\
\hline & Knowledge protection & {$[15]$} & \\
\hline \multirow[t]{4}{*}{ Commitment } & Participation & {$[16,17]$} & \\
\hline & $\begin{array}{l}\text { Commitment to } \\
\text { schedule }\end{array}$ & {$[18,19]$} & \\
\hline & Responsiveness & [20] & \\
\hline & $\begin{array}{l}\text { Percentage of } \\
\text { committed risk }\end{array}$ & & {$[10,21]$} \\
\hline \multirow[t]{3}{*}{$\begin{array}{l}\text { Communication } \\
\text { quality }\end{array}$} & $\begin{array}{l}\text { Effectiveness of } \\
\text { meetings }\end{array}$ & {$[22]$} & \\
\hline & $\begin{array}{l}\text { Openness of } \\
\text { communication } \\
\text { channels }\end{array}$ & {$[23]$} & \\
\hline & $\begin{array}{l}\text { Frequency of } \\
\text { knowledge sharing }\end{array}$ & & {$[10,24,25]$} \\
\hline
\end{tabular}


Table 2. (continued)

\begin{tabular}{l|l|l|l}
\hline Factors & Corresponding KPIs & $\begin{array}{l}\text { References with a } \\
\text { generic perspective }\end{array}$ & $\begin{array}{l}\text { References with a PSS } \\
\text { perspective }\end{array}$ \\
\hline \multirow{2}{*}{$\begin{array}{l}\text { Project } \\
\text { coordination }\end{array}$} & $\begin{array}{l}\text { Reciprocity in } \\
\text { knowledge sharing }\end{array}$ & $\begin{array}{l}\text { Percentage of customer } \\
\text { data collection }\end{array}$ & {$[10,24,25]$} \\
\cline { 2 - 4 } & Planning adjustment & {$[18]$} & {$[2]$} \\
\cline { 2 - 4 } & $\begin{array}{l}\text { Conflict solving } \\
\text { Percentage of } \\
\text { involvement of use } \\
\text { phase departments in } \\
\text { early design }\end{array}$ & {$[18,26]$} & {$[2,3]$} \\
\hline $\begin{array}{l}\text { Shared } \\
\text { language }\end{array}$ & $\begin{array}{l}\text { Percentage of mutual } \\
\text { adaptations }\end{array}$ & {$[10,27]$} \\
\cline { 2 - 4 } & $\begin{array}{l}\text { Percentage of adequacy } \\
\text { of standards }\end{array}$ & {$[10]$} \\
\hline
\end{tabular}

We argue that the KPIs adapted from references with a generic perspective can be applied to PSS context. Indeed, the activity of the partners in a PSS development project generally come from conventional business fields (e.g. an OEM in automotive industry who wants to add specific services needs complementary skills) [12]. In addition, Zhang (2017) [7] proved that the effect of social capital (i.e. trust) on operational performance is higher in the PSS context.

On the other hand, the KPIs adapted from references with a PSS perspective highlight some organizational characteristics of PSS that need to be considered.

Yet, the suitability of the KPIs was assessed by interviewees from two previous case studies (Case B and C). The result of this process is presented in Table 2.

\subsection{Building Membership Functions Using Fuzzy Techniques}

The next step of the proposed methodology is the use of fuzzy techniques for the construction of the assessment system. The choice of this tool is leaded by the capacities of fuzzy techniques to counter ambiguity and imprecision problems in calculations, and the possibility to use linguistic terms instead of precise numerical values [28], especially in solving socioeconomic problems. This choice is also inspired from Ayadi et al. (2013) [28], who used fuzzy techniques to assess trust level between partners in supply chain. Thus, we start by defining the membership functions, by considering the KPI as inputs, and the different success factors of collaboration performance as outputs. A mix of triangular and trapezoidal functions is chosen for the representation of the membership function. This choice is leaded by the suitability of these functions to represent human factors [28]. They are also widely used in practice [28, 29], which is explained by Barua et al. (2014) [29] using an interval-based theory. The different values of membership 


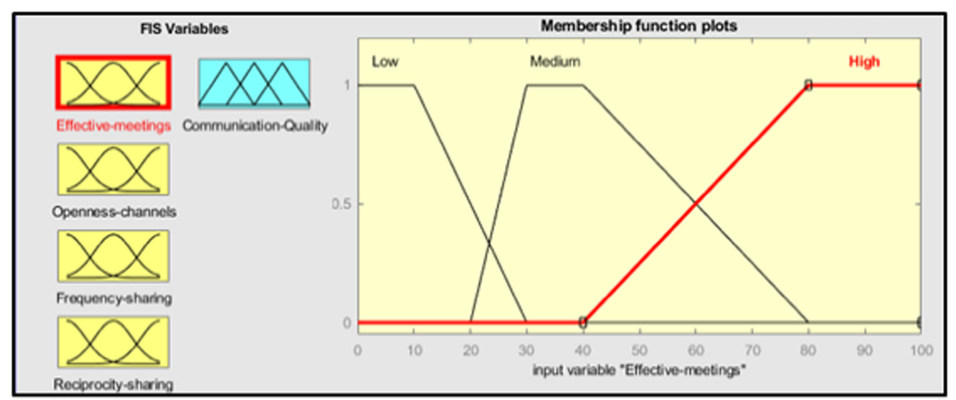

Fig. 2. Illustrative membership functions "Effectiveness of meetings"

functions are chosen with an intuition method based on the experience of the authors and will be validated in a further step through in-depth case studies.

We illustrate this step with the example of the input "Effectiveness of meetings" which is one of the KPIs of the output "Communication Quality" (Fig. 2). The input variable is represented by the following formula:

Effectiveness of meetings $=$ (Number of meetings conducting to ideation or decision making)/(Total number of meetings).

Three MFs are defined to describe the value of transaction costs: Low $(0,0,10,30)$, medium $(20,30,40,75)$ and high $(40,80,100,100)$. In this way, all the presented KPIs as inputs and the factors as outputs have their defined membership functions.

\subsection{Inference Rules Definition}

The next step of the methodology is to generate fuzzy inference rules, by using Mamdani's fuzzy inference method which is considered suitable for human inputs [28]. To improve the reliability of the assessment, the definition of these rules is performed by a combination of two iterations, which correspond to two methods presented in the literature. In the first iteration, we conduct a survey from which we extract data by using decision trees (C4.5 learning system). Decision trees provide a well-understood mechanism for inducing classification rules from data, as suggested by Hall and Lande (1998) [30]. Secondly, we involve experts for rules definition and adjustment, by using semistructured interviews, which is a widely presented method and recommended by Ayadi et al. (2013) [28].

In the first iteration, we performed a survey through a structured questionnaire from where we extract data by using the data mining process.

Data Collection. For the purpose of data collection, we performed an online survey targeting people who already worked in a multi-partner project for product and/or service delivery. The questionnaire was sent to 353 people from three different networks of engineering schools. Thus, 67 responses were received, which constitutes a response rate of $19 \%$. Respondents were asked to consider 1 to 3 partners in their answers. Among 67, 54 respondents considered 2 partners, while 40 considered 3 partners. This results 
to a total of 161 partners considered in the responses, which increase the data size to be used in the data mining process. Tables 3 show the composition of the sample.

Table 3. Composition of the sample

\begin{tabular}{l|l|l|l|l|l}
\hline \multicolumn{3}{l|}{ Geographical position } & \multicolumn{3}{l}{ Solution type } \\
\hline France & 33 & $49 \%$ & Product(s) & 28 & $42 \%$ \\
\hline Africa & 12 & $18 \%$ & Service(s) & 11 & $16 \%$ \\
\hline Europe (other) & 7 & $10 \%$ & $\begin{array}{l}\text { Product } \\
\text { oriented } \\
\text { PSS }\end{array}$ & 14 & $21 \%$ \\
\hline USA & 6 & $9 \%$ & $\begin{array}{l}\text { Use } \\
\text { oriented } \\
\text { PSS }\end{array}$ & 3 & $4 \%$ \\
\hline Asia/Oceania & 4 & $6 \%$ & $\begin{array}{l}\text { Result } \\
\text { oriented } \\
\text { PSS }\end{array}$ & 11 & $16 \%$ \\
\hline Germany & 4 & $6 \%$ & & & \\
\hline $\begin{array}{l}\text { America } \\
\text { (other) }\end{array}$ & 1 & $1 \%$ & & &
\end{tabular}

Extraction of Inference Rules. First, from the continuous input and output variables, classes were created to express intervals, which are necessary to build decision trees [30]. These classes correspond to the membership functions (e.g., low, medium, high) as shown in the third step of the methodology (Fig. 2).

Decision trees are then generated based on our survey data. The output factors (trust, commitment, communication quality, coordination, shared language) are considered as target variables, and their corresponding KPIs are put as attributes. After that, fuzzy rules are extracted by performing a depth search in the decision tree. The created rules correspond to each time a path reaches a leaf $[30,31]$. This process is illustrated by the following example in the decision tree generated for trust factor.

Based on the selected path from the C4.5 in Fig. 3, we formulate the following rule: IF Restriction of Marketing plans = severe AND History of Collaboration $=1$ year AND Pre-transaction costs $=$ (medium OR high OR very high) AND Restriction of technical information $=($ partial OR severe $)$ THEN trust $=$ Medium.

The percentages shown in the figure represent the population responses' which match the rule, and should be considered to improve reliability of the rules.

In the second iteration, the ongoing work is to conduct semi-structured interviews with experts from industry to adjust the inference rules. The results allow the generation of rules describing the relation between the KPIs and the factors in a first time, and between the factors and collaboration performance in a second time. 


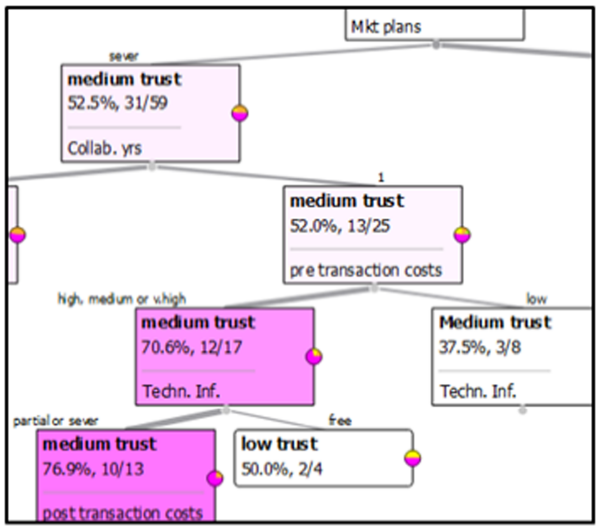

Fig. 3. Example of decision tree used for fuzzy rules generation

\section{Conclusion and Perspectives}

This paper proposes a methodology in four steps to build an assessment model for supporting inter-firm collaborations in PSS development and use phases. After ensuring the ability of partners to collaborate, the contribution of this framework is to assess the inter-firm relationships during the collaborations for PSS development and use phases. To do so, we first defined measures based on literature, and performed three case studies to validate them while analyzing industrial practices in terms of managing collaborations. The assessment system is built using fuzzy logic techniques. Furthermore, inference rules are created using decision trees by collecting data from a survey. The final step is the validation of the introduced framework through in-depth case studies. Indeed, the assessment model is currently being tested with industrials in order to make some adjustments. They are asked to enter values of the inputs to get the output value which is the performance of their collaboration in their PSS project. This assessment will finally allow the capitalization from their collaborations and the estimation of performance for future collaborations. This approach should help industrials to decide which strategy and improvement actions should be executed in order to collaborate effectively and to ensure the success of PSS delivery.

\section{References}

1. Tukker, A.: Eight types of product-service system: eight ways to sustainability? Exp. Suspronet. Bus. Strateg. Environ. 13, 246-260 (2004)

2. Wallin, J., Parida, V., Isaksson, O.: Understanding product-service system innovation capabilities development for manufacturing companies. J. Manuf. Technol. Manag. 26, 763-787 (2015)

3. Resta, B., Gaiardelli, P., Cavalieri, S., Dotti, S.: Enhancing the design and management of the product-service system supply chain: an application to the automotive sector. Serv. Sci. 9, 302-314 (2017) 
4. Mourtzis, D., et al.: Performance indicators for the evaluation of product-service systems design : a review. In: Umeda, S., Nakano, M., Mizuyama, H., Hibino, H., Kiritsis, D., von Cieminski, G. (eds.) Advances in Production Management Systems: Innovative Production Management Towards Sustainable Growth, pp. 592-601. Springer, Cham (2017). https://doi. org/10.1007/978-3-319-22759-7_68

5. Durugbo, C., Riedel, J.C.K.H.: Readiness assessment of collaborative networked organisations for integrated product and service delivery. Int. J. Prod. Res. 51, 598-613 (2013)

6. Johnsen, T.E., Johnsen, R.E., Lamming, R.C.: Supply relationship evaluation: the relationship assessment process (RAP) and beyond. Eur. Manag. J. 26, 274-287 (2008)

7. Zhang, M., Guo, H., Zhao, X.: Effects of social capital on operational performance: impacts of servitisation. Int. J. Prod. Res. 55, 4304-4318 (2017)

8. Baines, T., Shi, V.G.: A Delphi study to explore the adoption of servitization in UK companies. Prod. Plan. Control. 26, 1171-1187 (2015)

9. Reim, W., Parida, V., Örtqvist, D.: Product-Service Systems (PSS) business models and tactics - a systematic literature review. J. Clean. Prod. 97, 61-75 (2015)

10. Bastl, M., Johnson, M., Lightfoot, H., Evans, S.: Buyer-supplier relationships in a servitized environment: an examination with Cannon and Perreault's framework. Int. J. Oper. Prod. Manag. 32, 650-675 (2012)

11. Varoutsa, E., Scapens, R.W.: The governance of inter-organisational relationships during different supply chain maturity phases. Ind. Mark. Manag. 46, 68-82 (2015)

12. Harrat, M., Belkadi, F., Bernard, A.: Towards a modeling framework of collaboration in PSS development project: a review of key factors. Procedia CIRP. 90, 736-741 (2020)

13. Dyer, J.H., Chu, W.: The role of trustworthiness in reducing transaction costs and improving performance: empirical evidence from the United States, Japan, and Korea. Organ. Sci. 14, 57-68 (2003)

14. Belkadi, F., Messaadia, M., Bernard, A., Baudry, D.: Collaboration management framework for OEM - suppliers relationships: a trust-based conceptual approach. Enterp. Inf. Syst. 11, $1-25$ (2016)

15. Jean, R.J.B., Sinkovics, R.R., Hiebaum, T.P.: The effects of supplier involvement and knowledge protection on product innovation in customer-supplier relationships: a study of global automotive suppliers in China. J. Prod. Innov. Manag. 31, 98-113 (2014)

16. Servajean-Hilst, R.: Necessary governing practices for the success (and failure) of clientsupplier innovation cooperation. In: Moreira, A.C., Ferreira, L.M.D.F., Zimmermann, R.A. (eds.) Innovation and Supply Chain Management. CMS, pp. 79-100. Springer, Cham (2018). https://doi.org/10.1007/978-3-319-74304-2_4

17. Wibisono, Y.Y., Govindaraju, R., Irianto, D., Sudirman, I.: Interaction quality and the influence on offshore IT outsourcing success. In: Proceedings of 2017 International Conference on Data and Software Engineering. ICoDSE 2017, January 2018, pp. 1-6 (2018)

18. Westphal, I., Thoben, K.-D., Seifert, M.: Measuring collaboration performance in virtual organizations. In: Camarinha-Matos, L.M., Afsarmanesh, H., Novais, P., Analide, C. (eds.) PRO-VE 2007. ITIFIP, vol. 243, pp. 33-42. Springer, Boston, MA (2007). https://doi.org/10. 1007/978-0-387-73798-0_4

19. Pemartín, M., Rodríguez-Escudero, A.I.: Is the formalization of NPD collaboration productive or counterproductive? Contingent effects of trust between partners. BRQ Bus. Res. Q. 24, 2-18 (2020)

20. Davis-Sramek, B., Omar, A., Germain, R.: Leveraging supply chain orientation for global supplier responsiveness: the impact of institutional distance. Int. J. Logist. Manag. 30, 39-56 (2019)

21. Zou, W., Brax, S.A., Rajala, R.: Complexity in product-service systems: review and framework. Procedia CIRP 73, 3-8 (2018) 
22. Chirumalla, K., Bertoni, A., Parida, A., Johansson, C., Bertoni, M.: Performance measurement framework for product-service systems development: a balanced scorecard approach. Int. J. Technol. Intell. Plan. 9, 146-164 (2013)

23. Norman, P.M.: Protecting knowledge in strategic alliances resource and relational characteristics. J. High Technol. Manag. Res. 13, 177-202 (2002)

24. Kohtamäki, M., Partanen, J.: Co-creating value from knowledge-intensive business services in manufacturing firms: the moderating role of relationship learning in supplier - customer interactions. J. Bus. Res. 69, 2498-2506 (2016)

25. Weigel, S., Hadwich, K.: Success factors of service networks in the context of servitization - development and verification of an impact model. Ind. Mark. Manag. 74, 254-275 (2018)

26. Wu, G., Liu, C., Zhao, X., Zuo, J.: Investigating the relationship between communicationconflict interaction and project success among construction project teams. Int. J. Proj. Manag. 35, 1466-1482 (2017)

27. Li, H., Yang, Y., Singh, P., Sun, H., Tian, Y.: Servitization and performance: the moderating effect of supply chain integration. Prod. Plan. Control. 0, 1-18 (2021).

28. Ayadi, O., Cheikhrouhou, N., Masmoudi, F.: A decision support system assessing the trust level in supply chains based on information sharing dimensions. Comput. Ind. Eng. 66, 242257 (2013)

29. Barua, A., Mudunuri, L.S., Kosheleva, O.: Why trapezoidal and triangular membership functions work so well: towards a theoretical explanation. J. Uncertain Syst. 8, 164-168 (2014)

30. Hall, L.O., Lande, P.: Generation of fuzzy rules from decision trees. J. Adv. Comput. Intell. Intell. Inform. 2, 128-133 (1998)

31. Das, A., Desarkar, A.: Decision tree-based analytics for reducing air pollution. J. Inf. Knowl. Manag. 17, 1-20 (2018) 